\title{
Mean Platelet Volume as an Independent Predictive Marker for Pathologic Complete Response after Neoadjuvant Chemotherapy in Patients with Locally Advanced Breast Cancer
}

\author{
Hasan Mutlu' ${ }^{1}$, Melek Karakurt Eryılmaz ${ }^{1 *}$, Fatma Yalçcn Musri ${ }^{1}$, Seyda \\ Gunduz $^{2}$, Derya Kıvrak Salim ${ }^{1}$, Hasan Senol Coskun ${ }^{1}$
}

\begin{abstract}
Background: The impact of mean platelet volume (MPV) on prognosis, diagnosis and response to therapy in cancer patients has been widely investigated. In the present study, we evaluated whether MPV at diagnosis has predictive value for pathologic complete response (pCR) after neoadjuvant chemotherapy in patients with locally advanced breast cancer (LABC). Materials and Methods: A total of 109 patients with LABC from Akdeniz University and Antalya Research and Training Hospital were evaluated retrospectively. Results: ROC curve analysis suggested that the optimum MPV cut-off point for LABC patients with pCR (+) was 8.15 (AUC:0.378, 95\% CI [0.256- 0.499], $\mathrm{p}=0.077)$. The patients with MPV $<8.15$ had higher $\mathrm{pCR}$ rates $(29.2 \%$ vs. 13.1\%, $\mathrm{p}=0.038)$. After binary logistic regression analysis, MPV and estrogen receptor absence were independent predictors for pCR. Conclusions: MPV has an independent predictive value for pCR after neoadjuvant chemotherapy in patients with $\mathrm{LABC}$.
\end{abstract}

Keywords: Mean platelet volume - pathologic complete response - breast cancer - neoadjuvant chemotherapy

Asian Pac J Cancer Prev, 17 (4), 2089-2092

\section{Introduction}

Breast cancer (BC) is the most common type of malignancies in women (Ferlay et al., 2015). In order to improve the survival of patients with $\mathrm{BC}$ systemic therapies (chemotherapy or hormonal therapy) are suggested to the patients after surgery. Sometimes upfront systemic treatment (neoadjuvant chemotherapy (NACT)) may be suggested to the patients $\mathrm{BC}$ in whom a primary surgery is technically not feasible or breast conserving surgery is preferred in operable disease (Gralow et al., 2008). The pathologic complete response (pCR) is one of the most important outcomes after NACT because pCR have a predictive value for survival (Kong et al., 2011).

Thrombocytes play an important role in atherosclerotic complications and mean platelet volume (MPV) is accepted as an indicator of thrombocyte volume. Some studies were previously reported that there was wide platelets with dense granules, containing more thromboxane A2 resulted in tendency to thrombosis in the blood in the presence of increased MPV levels (Davi et al., 2007; Greisenegger et al., 2004).

In breast cancer like other cancer types, it is investigating whether MPV has a predictive or prognostic value (Yao et al., 2014). In the present study, we evaluated whether MPV has a predictive value for $\mathrm{pCR}$ after NACT in patients with $\mathrm{LABC}$.

\section{Materials and Methods}

A total of 109 patients with LABC from Akdeniz University and Antalya Research and Training Hospital were evaluated retrospectively. The age, menopausal status, MPV, histological type, tumor and nodal stage, the presence of estrogen reseptor (ER), progesterone reseptor (PR) and human epidermal growth factor receptor 2 (HER2) status, lymphovascular invasion (LVI), perineural invasion (PNI) and grade were recorded into the Statistical Package for the Social Sciences version 16.0 (SPSS 16.0) from the medical archives retrospectively.

To determine the properties of patients with LABC, frequency analysis, two independent samples t test, and chi-square tests were performed. The capacity of MPV in predicting pCR (breast and axillary) to NACT in patients with $\mathrm{BC}$ was analyzed using receiver operating characteristic (ROC) curve analysis. Optimal cut-off 


\section{Hasan Mutlu et al}

values were determined. While evaluating the area under the curve, a5\% type-I error level was used to accept a statistically significant predictive value of the test variables. After univariate analysis to identify associated with PCR, for the multivariate analysis, the possible factors were further entered into logistic regression analysis to determine independent predictors of PCR. Hosmer-Lemeshow goodness of fit statistics were used to assess model fit. A $p$ value of $<0.05$ was considered significant.

\section{Results}

A total of 109 were retrospectively evaluated for MPV. ROC curve analysis suggested that the optimum MPV cut-off point for LABC patients with PCR (+) was 8.15 (AUC:0.378, 95\%CI [0.256- 0.499], $\mathrm{p}=0.077$ ) with sensitivity, specificity, positive predictive value, and negative predictive value of $63,6 \%, 60,9 \%, 29,2 \%$, and $86,9 \%$, respectively (Figure 1).

\section{ROC Curve}

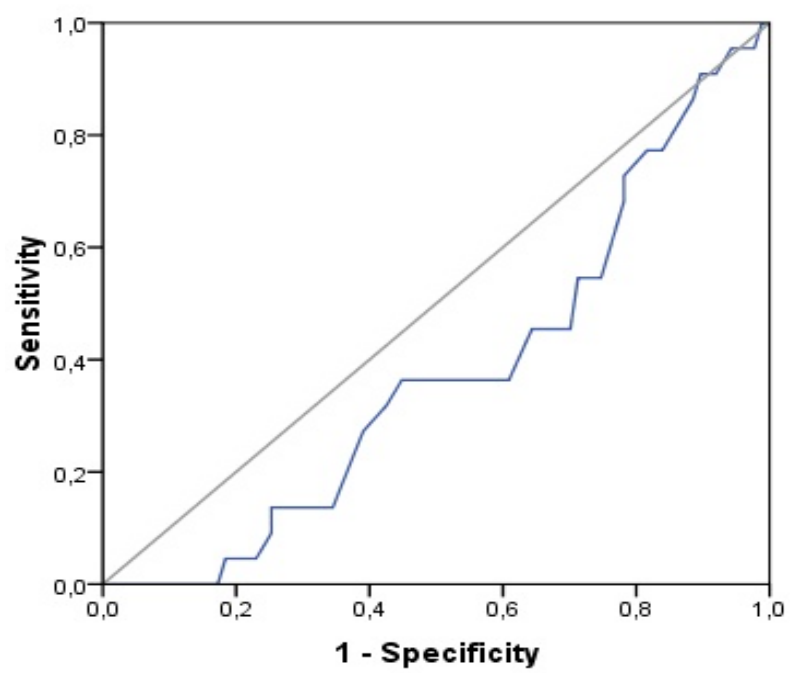

Figure 1. Receiver Operating Characteristic (ROC) Curves

Table 1. The characteristics of patients according to mean platelet volume $<8.15$ or $>8.15$

\begin{tabular}{|c|c|c|c|}
\hline & Patients with MPV $<8.15$ (n:48) & Patients with MPV $>8.15$ (n:61) & P Value \\
\hline Age(mean-years) & $47,4 \pm 8,3$ & $49,1 \pm 10,9$ & 0.379 \\
\hline Menopausal Status & & & 0.085 \\
\hline Premenopausal & $68.80 \%$ & $52.50 \%$ & \\
\hline Postmenopausal & $31.20 \%$ & $47.50 \%$ & \\
\hline Histologic type & & & 0.603 \\
\hline Invazıv Ductal Carcinom & $16.70 \%$ & $13.10 \%$ & \\
\hline Non-Invazıv Ductal Carcinom & $83.30 \%$ & $86.90 \%$ & \\
\hline T stage (Clinic) & & & 0.991 \\
\hline T0 & $2.10 \%$ & $1.60 \%$ & \\
\hline $\mathrm{T} 1$ & $4.20 \%$ & $3.30 \%$ & \\
\hline $\mathrm{T} 2$ & $45.80 \%$ & $45.90 \%$ & \\
\hline $\mathrm{T} 3$ & $18.80 \%$ & $16.40 \%$ & \\
\hline $\mathrm{T} 4$ & $29.20 \%$ & $32.80 \%$ & \\
\hline $\mathrm{N}$ stage (Clinic) & & & 0.333 \\
\hline No & $14.60 \%$ & $16.40 \%$ & \\
\hline N1 & $45.80 \%$ & $29.50 \%$ & \\
\hline $\mathrm{N} 2$ & $33.30 \%$ & $42.60 \%$ & \\
\hline N3 & $6.20 \%$ & $11.50 \%$ & \\
\hline Estrogen Receptor & & & 0.712 \\
\hline Positive & $62.50 \%$ & $59 \%$ & \\
\hline Negative & $37.50 \%$ & $41 \%$ & \\
\hline Progesteron Receptor & & & 0.392 \\
\hline Positive & $45.80 \%$ & $54.10 \%$ & \\
\hline Negative & $54.20 \%$ & $45.90 \%$ & \\
\hline CerbB2 receptor & & & 0.348 \\
\hline Positive & $40 \%$ & $41 \%$ & \\
\hline Negative & $50 \%$ & $59 \%$ & \\
\hline Lymphovasculer invasion & & & 0.062 \\
\hline Positive & $27.10 \%$ & $42.60 \%$ & \\
\hline Negative & $60.40 \%$ & $37.70 \%$ & \\
\hline Unknown & $12.50 \%$ & $19.70 \%$ & \\
\hline Perineural invasion & & & 0.602 \\
\hline Positive & $8.30 \%$ & $8.20 \%$ & \\
\hline Negative & $79.20 \%$ & $72.10 \%$ & \\
\hline Unknown & $12.50 \%$ & $19.70 \%$ & \\
\hline Grade & & & 0.708 \\
\hline Grade1 & $4.20 \%$ & $1.60 \%$ & \\
\hline Grade2 & $64.60 \%$ & $60.70 \%$ & \\
\hline Grade3 & $29.20 \%$ & $32.80 \%$ & \\
\hline Unknown & $2.10 \%$ & $4.90 \%$ & \\
\hline
\end{tabular}


The patients were divided into two groups according MPV: MPV <8.15 (n:48) and MPV>8.15 (n:61). When we evaluated the patients with LABC according to MPV, there was no difference between MPV $<8.15$ and MPV $>8.15$ groups regarding the mean age, menopausal status, histological type, clinical T stage, clinical $\mathrm{N}$ stage $(\mathrm{p}=0.379, \mathrm{p}=0.085, \mathrm{p}=0.603, \mathrm{p}=0.991$, and $\mathrm{p}=0.333$, respectively). The ratio of ER, PR and HER 2 positivity were similar between groups $(\mathrm{p}=0.712, \mathrm{p}=0.392$ and $\mathrm{p}=0.348$, respectively). Also it was not found any significant difference regarding LVI, PNI and grade $(\mathrm{p}=0.062, \mathrm{p}=0.602$ and $\mathrm{p}=0.708$, respectively). According to $\mathrm{MPV}<8.15$ and $>8.15$, the properties of patients were given in Table 1.

When evaluating the factors had a independently predictive value for PCR, the absence ER positivity and MPV were found as independent predictors ( $\mathrm{p}=0.004$ and $\mathrm{p}=0.046$, respectively).

\section{Discussion}

In the present study, we investigated whether MPV at diagnosis has a predictive value for $\mathrm{PCR}$ after NACT in patients with $\mathrm{LABC}$. We found a significant difference between groups in terms of pCR according to MPV $(<8.15$ or $>8.15$ ). The patients with LABC in whom MPV $<8.15$ at diagnosis had higher pCR rates after NACT than other patients with MPV $>8.15$. To our knowledge, this is the first study to demonstrate the relationship between MPV and pCR after NACT in patients with LABC.

Generally, it is known that larger MPV is correlated thromboembolic events (Sansanayudh N et al., 2014; Han JS et al., 2013; Canan A et al., 2012). In previously presented studies, according to MPV, it was reported different outcomes in cancer patients in terms of prognosis (Dirican A et al., 2013; Tuncel T et al., 2014; Inagaki $\mathrm{N}$ et al., 2014; Aliustaoglu M et al., 2014). The cancer mortality is mostly dependent infection and thromboembolic events, therefore MPV be important a predictive and prognostic factor for cancer patients.

In patients with $\mathrm{LABC}$, the $\mathrm{pCR}$ after NACT predict survival advantage especially HER2 like and triple negative groups (Berruti A et al., 2014; von Minckwitz $\mathrm{G}, 2013)$. In previously, some factors were reported as predictive factors of $\mathrm{pCR}$ to NACT. The breast cancer with grade 3 or higher $\mathrm{Ki}-67$ expression is more responsive to NACT associated with higher pCR rates (Colleoni et al., 2004; Cristofanilli et al., 2005). Also, pCR are associated with absence of ER and PR expression (Cristofanilli et al., 2005). The histological type was one of them and when compared with invasive ductal carcinoma, $\mathrm{pCR}$ ratio was lower in invasive lobular carcinoma (Kim et al., 2014). Additionally, NACT agents are also important for the pCR. It has reported that taxan addition to an anthracyclinecontaining regimen, dose dens-intensified treatment and trastuzumab addition in HER2 positive tumors have increased the ratio of pCR (Berruti et al., 2014; Bear et al., 2006; Buzdar et al., 2005).

Inflammation based markers have investigated and been shown that they were a predictor for chemotherapy response (Krauthamer et al., 2013; Noble et al., 2013;
Guthrie et al., 2013; Kobayashi et al., 2008). In the most of these studies, higher inflammation scores were associated with poorer outcomes (Yao et al., 2014; Pistelli et al., 2015). It was reported that the higher inflammation markers were associated with worst outcome or poorer survival in studies performed in patients with BC (Kobayashi et al., 2008; Pistelli et al., 2015). Also, lower PCR rates have been showed in patients with higher inflammation markers in neoadjuvant setting (Eryilmaz et al., 2014; Koh et al., 2014).

MPV is accepted one of the inflammatory markers, such as the neutrophil-lymphocyte ratio (NLR), plateletlymphocyte ratio, $\mathrm{C}$-reactive protein and serum albumin levels (Sansanayudh et al., 2014). Higher MPV is associated with comorbidities (Madan et al., 2016). According to our study, lower MPV has predicted higher PCR rates and it was an independent predictor.

In conclusion, we speculate that MPV may be used as a predictor to decide NACT in the borderline patients with BC.

\section{References}

Aliustaoglu M, Bilici A, Seker M, et al (2010). The association of pre-treatment peripheral blood markers with survival in patients with pancreatic cancer. Hepatogastroenterol, 5 , 640-45.

Bear HD, Anderson S, Smith RE, et al (2006). Sequential preoperative or postoperative docetaxel added to preoperative doxorubicin plus cyclophosphamide for operable breast cancer:National Surgical Adjuvant Breast and Bowel Project Protocol B-27. J Clin Oncol, 24, 2019-27.

Berruti A, Amoroso V, Gallo F, et al (2014). Pathologic complete response as a potential surrogate for the clinical outcome in patients withbreast cancer after neoadjuvant therapy: a meta-regression of 29 randomized prospective studies. $J$ Clin Oncol, 32, 3883-91.

Buzdar AU, Ibrahim NK, Francis D, et al (2005). Significantly higher pathologic complete remission rate after neoadjuvant therapy with trastuzumab, paclitaxel, and epirubicin chemotherapy: results of a randomized trial in human epidermal growth factor receptor 2-positive operable breast cancer. J Clin Oncol, 23, 3676-85.

Canan A, Halıcioğlu SS, Gürel S (2012). Mean platelet volume and D-dimer in patients with suspected deep venous thrombosis. J Thromb Thrombolysis, 34, 283-7.

Colleoni M, Viale G, Zahrieh D, et al (2004). Chemotherapy is more effective in patients with breast cancer not expressing steroid hormone receptors: a study of preoperative treatment. Clin Cancer Res, 10, 6622-8.

Cristofanilli M, Gonzalez-Angulo A, Sneige N, et al (2005). Invasive lobular carcinoma classic type: response to primary chemotherapy and survival outcomes. J Clin Oncol, 23, 41-8.

Davi G, Patrono C (2007). Platelet activation and atherothrombosis. NEngl Jmed, 357, 2482-94.

Dirican A, Kucukzeybek Y, Erten C, et al (2013). Prognostic and predictive value of hematologic parameters in patients with metastatic renal cell carcinoma: second line sunitinib treatment following IFN-alpha. Asian Pac J Cancer Prev, 14, 2101-5.

Eryilmaz MK, Mutlu H, Salim DK, et al (2014). The neutrophil to lymphocyte ratio has a high negative predictive value for pathologic complete response in locally advanced breast cancer patients receiving neoadjuvant chemotherapy. Asian Pac J Cancer Prev, 15, 7737-40. 


\section{Hasan Mutlu et al}

Ferlay J, Soerjomataram I, Dikshit R, et al (2012). Cancer incidence and mortality worldwide: sources, methods and major patterns in GLOBOCAN 2012. Int J Cancer, 136, 359-86.

Gralow JR, Burstein HJ, Wood W , et al (2008). Preoperative therapy in invasive breast cancer: pathologic assessment and systemic therapy issues in operable disease. J Clin Oncol, 26, 814-19.

Greisenegger S, Endler G, Hsieh K, et al (2004). Is elevated mean platelet volume associated with a worse outcome in patients with acute ischemic cerebrovascular events? Stroke, 35, 1688-91.

Guthrie GJ, Charles KA, Roxburgh CS, et al (2013). The systemic inflammation-based neutrophil-lymphocyte ratio: 45 experience in patients with cancer. Crit Rev Oncol Hematol, 88, 218-30.

Han JS, Park TS, Cho SY, et al (2013). Increased mean platelet volume and mean platelet volume/platelet count ratio in Korean patients with deep vein thrombosis. Platelets, 24, 590-3.

Inagaki N, Kibata K, Tamaki T, et al (2014). Prognostic impact of the mean platelet volume/platelet count ratio in terms of survival in advanced non-small cell lung cancer. Lung Cancer, 83, 97-101.

Kim KI, Lee KH, Kim TR, et al (2014). Ki-67 as a predictor of response to neoadjuvant chemotherapy in breast cancer patients. J Breast Cancer, 17, 40-6.

Kobayashi T,Teruya M,KishikiT, et al(2008).Inflammation-based prognostic score, prior to neoadjuvant chemoradiotherapy, predicts postoperative outcome in patients with esophageal squamous cell carcinoma. Surgery, 144, 729-35.

Koh YW, Lee HJ, Ahn JH, et al (2014). Prognostic significance of the ratio of absolute neutrophil to lymphocyte counts for breast cancerpatients with ER/PR-positivity and HER2negativity in neoadjuvant setting. Tumour Biol, 35, 9823-30.

Kong X, Moran MS, Zhang N, et al (2011). Meta-analysis confirms achieving pathological complete response after neoadjuvant chemotherapy predicts favourable prognosis for breast cancer patients. Eur J Cancer, 47, 2084-90.

Krauthamer M, Rouvinov K, Ariad S, et al (2013). A study of inflammation-based predictors of tumor response to neoadjuvant chemoradiotherapy for locally advanced rectal cancer. Oncol, 85, 27-32.

Madan SA, John F, Pitchumoni CS (2016). Nonalcoholic Fatty Liver Disease and Mean Platelet Volume: A Systemic Review and Meta-analysis. J Clin Gastroenterol, 50, 69-74.

Noble F, Hopkins J, Curtis N, et al (2013). The role of systemic inflammatory and nutritional blood-borne markers in predicting response to neoadjuvant chemotherapy and survival in oesophagogastric cancer. Med Oncol, 30, 596.

Pistelli M, De Lisa M, Ballatore Z, et al (2015). Pre treatment neutrophil to lymphocyte ratio may be a useful tool in predicting survival in early triple negative breast cancer patients. BMC Cancer, 15, 195.

Sansanayudh N, Anothaisintawee T, Muntham D, et al (2014). Mean platelet volume and coronary artery disease: a systematic review and meta-analysis. Int J Cardiol, 175, 433-40.

Tuncel T, Ozgun A, Emirzeoglu L, et al (2014). Mean platelet volume as a prognostic marker in metastatic colorectal cancer patients treated with bevacizumab-combined chemotherapy. Asian Pac J Cancer Prev, 15, 6421-23.

von Minckwitz G (2013). Neoadjuvant therapy: what are the lessons so far? Hematol Oncol Clin North Am, 27, 767-84.

Yao M, Liu Y, Jin H, et al (2014). Prognostic value of preoperative inflammatory markers in Chinese patients with breast cancer. Onco Targets Ther, 7, 1743-52. 